\title{
Characteristics And Temporal Variations Of Organic And Elemental Carbon Aerosols In A High-Altitude, Tropical Latin American Megacity
}

Ramirez Hernandez, Omar Javier; Sánchez De La Campa, Ana María; De La Rosa, Jesús D.

\section{Abstract}

Bogota is a Latin American megacity located at an average altitude of $2600 \mathrm{~m}$ in the tropical Andes. It registers frequent episodes of poor air quality due to high $\mathrm{PM}_{10}$ concentrations. The carbonaceous fraction is the main $\mathrm{PM}_{10}$ component $(>50 \%)$, but there is a lack of specific studies analyzing the characteristics and temporal variability of organic carbon (OC) and elemental carbon (EC) aerosols. In this study, daily samples (24 $\pm 1 \mathrm{~h}$ ) were collected from June 2015 to May 2016 (a total of 308 samples) at an urban background site during an EI Niño year, and the quartz filters were analyzed using a thermal-optical method. Results showed that EC and organic matter accounted for $\sim 60 \%$ of the PM10 mass. The OC and EC averages were $8.92 \pm 4.52 \mu \mathrm{g} / \mathrm{m}^{3}$ and $3.25 \pm 1.59 \mu \mathrm{g} / \mathrm{m}^{3}$, respectively. The months with the highest average OC values were January to March, while EC concentrations were relatively constant throughout the year. Regarding daily values, the highest mean concentrations of OC $\left(10.2 \pm 5.13 \mu \mathrm{g} / \mathrm{m}^{3}\right)$ and EC $(3.73 \pm$ $\left.1.74 \mu \mathrm{g} / \mathrm{m}^{3}\right)$ were obtained on Thursdays, and the lowest on Sundays $(\mathrm{OC}=6.67 \pm$ $3.04 \mu \mathrm{g} / \mathrm{m}^{3}$ and $\mathrm{EC}=2.46 \pm 0.94 \mu \mathrm{g} / \mathrm{m}^{3}$ ). The OC/EC ratio ranged from 1.66 (June) to 4.88 (March), with an annual average of $3.16 \pm 2.01$. The secondary organic carbon (SOC) contributions, measured using the EC-tracer method, accounted for $45 \%$ of the total OC. The effective carbon ratio, which indicates an association between carbonaceous particles and climate change, ranged from 0.12 (July) to 0.74 (May). The study of air-mass origins revealed that days with air mass from $E+$ $\mathrm{NE}$ registered the highest $\mathrm{OC}$ concentrations. This research provides new data on the variability of carbonaceous aerosols over the course of a year. It also highlights forest fires as a significant source of $\mathrm{OC}$ and $\mathrm{EC}$, and indicates the high impact of $\mathrm{SOC}$ on OC concentration at the sampling site.

\section{Keywords}

Carbonaceous Aerosol; Colombia; El Niño; Megacity; OC/EC; PM10. 